CLINICAL STUDY

\title{
Influence of pegvisomant on serum ghrelin and leptin levels in acromegalic patients
}

\author{
J Roemmler, B Otto, A M Arafat ${ }^{1}$, M Bidlingmaier and J Schopohl \\ Department of Internal Medicine (Endocrinology) - Innenstadt, LM-University of Munich, Ziemssenstrasse 1, 80336 Munich, Germany and ${ }^{1}$ Department \\ of Endocrinology, Diabetes and Nutrition, Charité-University Medicine Berlin, Campus Benjamin Franklin, 12203 Berlin, Germany \\ (Correspondence should be addressed to J Roemmler; Email: josefine.roemmler@med.uni-muenchen.de)
}

\begin{abstract}
Introduction: Pegvisomant (peg) is a GH receptor antagonist. In de novo acromegalic patients with high GH levels, ghrelin and leptin levels are reduced, suggesting a direct GH-mediated effect. The aim of our study was to evaluate whether peg treatment in acromegalic patients may abolish the GH impact on ghrelin and leptin levels.

Methods: Ghrelin, leptin and endogenous GH were measured in ten peg-treated acromegalic patients (three females/seven males, 47 years (28-57)), ten patients with active (act) and ten patients with inactive disease (inact) as well as in ten gender-, age- and body mass index (BMI)-matched healthy volunteers (controls). Endogenous GH was measured using a special in-house assay without interference by peg; total ghrelin and leptin were determined using a commercial RIA and an immunofluorometric in-house assay respectively.

Results: Age and BMI did not differ significantly between groups. Endogenous GH was significantly higher in peg $(6.3 \mu \mathrm{g} / \mathrm{l}(1.5-41))$ and act $(9.3 \mu \mathrm{g} / \mathrm{l}(1.7-70))$ compared with controls $(0.1 \mu \mathrm{g} / \mathrm{l}$ $(0.1-3.1))$ and inact $(0.35 \mu \mathrm{g} / \mathrm{l}(0.1-2.0), P<0.001)$. Ghrelin was significantly higher in peg (232 ng/l (96-351)) compared with act (102 ng/l (33-232), P<0.01), whereas ghrelin was not significantly different between the other groups. Leptin was highest in controls $(19 \mu \mathrm{g} / \mathrm{l}(4-57))$ and lowest in act $(6 \mu \mathrm{g} / \mathrm{l}(2-21))$, but this difference did not reach significance.

Conclusion: Treatment with peg seems to disrupt the feedback loop of ghrelin and GH, leading to elevated ghrelin levels. Furthermore, peg therapy appears not to have a strong impact on leptin levels, as acromegalic patients with and without peg treatment showed similar leptin levels.
\end{abstract}

European Journal of Endocrinology 163 727-734

\section{Introduction}

The GH receptor antagonist pegvisomant (peg) is a treatment option for acromegaly, if disease activity could be adequately controlled by other treatments such as surgery, somatostatin analogues or dopamine agonists $(1,2)$. It is a pegylated human $\mathrm{GH}$ analogue, which blocks the GH receptor (3). It normalizes insulinlike growth factor 1 (IGF1) levels in $80-90 \%$ of active (act) acromegalic patients $(2,4)$. During peg treatment, $\mathrm{GH}$ levels rise in a dose-dependent manner (2). As peg interferes with most of the conventional GH assays (5), new assays have been developed to measure endogenous GH without any cross-reactivity with the drug (6).

Some studies suggest that peg treatment improves insulin sensitivity in acromegaly (7-9), reduces free fatty acid concentrations (9) and suppresses lipid mobilization and oxidation (10). Intra-abdominal fat mass, a cardiovascular risk marker, seems to be increased during peg therapy (11). But other studies showed that fat metabolism is not altered by peg $(8,12)$.
Leptin and ghrelin are metabolic hormones influencing fat mass, food intake, body composition and energy expenditure $(13,14)$. Leptin levels are high in adiposity as the hormone is secreted by fat cells (13). Appetite is reduced due to high leptin levels by inhibition of hypothalamic neuropeptide Y (15). Conversely, ghrelin is a hunger hormone, whose levels are high during fasting and are reduced by food intake $(16,17)$. Ghrelin is produced in the gastrointestinal tract in the endocrine X/A-like cells of the gastric mucosa (18). It is also produced in the hypothalamus and stimulates GH secretion in the pituitary $(19,20)$. On the other hand, ghrelin can be reduced by $\mathrm{GH}$. This could be shown in some $(21,22)$, but not all, studies (23) in act acromegaly where GH levels are elevated, as well as after $\mathrm{GH}$ substitution in $\mathrm{GH}$ deficiency (24) and in rats (25). After surgical cure, reduced ghrelin levels in acromegaly increase (26), whereas ghrelin levels are still low during somatostatin analogue therapy even if $\mathrm{GH}$ and IGF1 levels are normalized (27). 
In act acromegalic patients, leptin levels are reduced (28), and disease control after surgery (29) or during somatostatin analogue treatment (30) has been shown to increase leptin levels. Furthermore, leptin and GH seem to directly interact $(28,31)$.

Only few studies have investigated the influence of peg on ghrelin (32) and leptin levels (33).

We performed this cross-sectional study to evaluate the influence of peg on ghrelin and leptin levels by comparing acromegalic patients treated with peg to healthy controls (controls), acromegalic patients treated with act disease and those patients treated with inactive (inact) disease after surgery. Our question was whether peg prevents the reducing influence of $\mathrm{GH}$ on ghrelin levels. Furthermore, we investigated whether the inhibition of lipolytic GH effects by peg leads to an increase in leptin levels.

\section{Subjects and methods}

\section{Subjects}

All patients with acromegaly currently treated with the GH receptor antagonist peg as monotherapy attending our outpatients' clinic were informed about this crosssectional study. Eight patients agreed to participate (two females and six males). Furthermore, two patients of the Max Planck Institute of Psychiatry (Department of Endocrinology, Munich, Germany) were included in this study (one female and one male). After having obtained informed consent, altogether ten patients were included in the study. The investigation was reviewed and approved by the ethics committee of the Medical Faculty of the LMU Muenchen. Moreover, ten gender-, age- and body mass index (BMI)-matched healthy volunteers examined at the Charité - University Medicine in Berlin, ten acromegalic patients with act disease and ten acromegalic patients with inact disease without any medical treatment examined at our clinic were referred to as control groups. Acromegalic patients with inact disease activity are defined as patients with an IGF1 level within the age- and gender-adjusted normal range (upper limit of normal $=x U L N$ ) and $\mathrm{GH}$ nadir during an oral glucose tolerance test (OGTT) beyond $0.5 \mu \mathrm{g} / \mathrm{l}$ after pituitary surgery alone. The patients were not treated with any medication for acromegaly and had not received pituitary radiation. All patients on peg, all patients with inact disease and two patients with act disease had transsphenoidal surgery. Six patients on peg, but none of the other acromegalic patients, had received additional conventional radiotherapy. All patients on peg had been on somatostatin analogue therapy before. None of the acromegalic patients with act or inact disease were currently on any medication for acromegaly.

Median duration of peg treatment before study entry was 27 months (range 1-47 months) with a median dose of $15 \mathrm{mg}$ (range 10-30 mg). Seven patients (70\%) had $x U L N \leq 1$ and were therefore defined as in remission. Out of the three patients who were not in remission (xULN $>1$ ), two patients had a xULN of IGF1 below two times ULN and one patient had a xULN of IGF1 above two times ULN.

Seven patients on peg, seven patients with act disease and five patients with inact disease had partial pituitary insufficiency. For further details, see Table 1.

Patients with diabetes mellitus currently on insulin therapy were excluded from the study. One female patient on peg had diabetes mellitus type II (Dm II) and was treated with diet and metformin. One female patient with act disease had Dm II and was treated with pioglitazone and metformin; another female patients had yet untreated impaired glucose tolerance. None of the patients with inact disease had Dm. See Tables 1 and 2 for more patients' characteristics.

\section{Methods}

Patients arrived between 0700 and $0900 \mathrm{~h}$ after overnight fasting for evaluation. First, baseline data including medical history, physical examination and basal blood samples for haematology, clinical chemistry

Table 1 Characteristics of all patients of the four groups. Data are given as median and range.

\begin{tabular}{llllll}
\hline & Peg & Controls & Act & Inact & P value \\
\hline Gender $(\mathrm{F} / \mathrm{M})$ & $3 / 7$ & $3 / 7$ & $3 / 7$ & $4 / 6$ & - \\
Operation $(n)$ & 10 & - & 2 & 10 & \\
Pituitary insuff & 7 & - & 8 & 5 & \\
Corticotrope & 6 & - & 2 & 4 & \\
Gonadotrope & 6 & - & 7 & 1 & \\
Thyreotrope & 3 & - & 0 & 1 & \\
Complete & 2 & $46(27-59)$ & $48(33-80)$ & $49(33-60)$ & $\mathrm{NS}$ \\
Age $(\mathrm{yrs})$ & $47(28-57)$ & $31(26-35)$ & $29(26-36)$ & $30(25-35)$ & $\mathrm{NS}$ \\
BMI $\left(\mathrm{kg} / \mathrm{m}^{2}\right)$ & $30(25-36)$ & $90(78-99)$ & $102(86-113)$ & $95(69-103)$ & $\mathrm{NS}$ \\
Glucose (mg/dl) & $87(71-97)$ & $18(15-29)$ & $11(6-42)$ & $12(3-24)$ & NS \\
Insulin $(\mu \mathrm{U} / \mathrm{ml})$ & $13(7-25)$ & $0.5(0.4-0.7)$ & $3.6(1.5-6.1)$ & $0.5(0.3-1.0)$ & $<0.001$ \\
xULN $(\mathrm{IGF} 1)$ & $0.8(0.5-2.7)$ & & & & \\
\hline
\end{tabular}

$n$, number of patients; yrs, years; F, female; M, male; pituitary insuff, pituitary insufficiency; BMI, body mass index; IGF1, insulin-like growth factor 1 ; NS, not significant. 
Table 2 Characteristics of patients on pegvisomant treatment.

\begin{tabular}{|c|c|c|c|c|c|c|c|c|}
\hline Patient & Sex & $\begin{array}{c}\text { Age } \\
\text { (years) }\end{array}$ & $\begin{array}{c}\text { BMI } \\
\left(\mathrm{kg} / \mathrm{m}^{2}\right)\end{array}$ & $\begin{array}{l}\text { xULN } \\
(\text { IGF1) }\end{array}$ & $\begin{array}{l}\text { Radiotherapy } \\
\text { (years) }\end{array}$ & $\begin{array}{l}\text { peg duration } \\
\text { (months) }\end{array}$ & $\begin{array}{l}\text { peg dose } \\
\text { (mg/day) }\end{array}$ & Dm \\
\hline 1 & $\mathrm{~F}$ & 53 & 34 & 0.8 & 2000 & 41 & 10 & Metformin \\
\hline 2 & $\mathrm{~F}$ & 44 & 28 & 0.5 & 1998, 2002, 2004 & 34 & 20 & No \\
\hline 3 & $\mathrm{~F}$ & 55 & 31 & 0.8 & No & 47 & 30 & No \\
\hline 4 & $\mathrm{M}$ & 44 & 28 & 0.8 & 2002 & 29 & 15 & No \\
\hline 5 & M & 55 & 36 & 2.7 & 1976 & 1 & 20 & No \\
\hline 6 & M & 50 & 29 & 0.7 & 2004 & 25 & 10 & No \\
\hline 7 & M & 43 & 33 & 1.4 & No & 25 & 15 & No \\
\hline 8 & M & 34 & 30 & 1.0 & 1996 & 18 & 15 & No \\
\hline 9 & $\mathrm{M}$ & 28 & 25 & 1.6 & No & 12 & 15 & No \\
\hline 10 & $M$ & 57 & 30 & 0.7 & No & 41 & 10 & No \\
\hline
\end{tabular}

F, female; M, male; BMI, body mass index; IGF1, insulin-like growth factor 1; peg, pegvisomant; Dm, diabetes mellitus II.

and endocrine parameters including IGF1 were taken. Afterwards, an OGTT was performed according to the World Health Organization criteria. Serum leptin, ghrelin, endogenous GH, glucose and insulin concentrations were collected at time points $0,30,60,120$ and $180 \mathrm{~min}$ following $75 \mathrm{~g}$ glucose (Dextro O.G.-T., Roche) administration. Blood samples were immediately chilled and centrifuged at $4{ }^{\circ} \mathrm{C}$, and serum aliquots were frozen until assayed.

\section{Laboratory values}

A specific assay was designed to monitor endogenous $\mathrm{GH}$ secretion in patients treated with the GH analogue peg. This assay is free of interference with the drug peg and has been validated, and it is described in detail elsewhere $(3,6,32)$. To ensure comparability, GH was measured for all patients in this special assay. The lower detection limit was $0.2 \mu \mathrm{g} / \mathrm{l}$, and the upper end of the linear working range was $50 \mu \mathrm{g} / \mathrm{l}$ for $50 \mu \mathrm{l}$ samples. Intra-assay variability was 4.1 and $3.9 \%$ at concentrations of 5.2 and $14.6 \mu \mathrm{g} / \mathrm{l}$ respectively. Inter-assay variability at the same concentrations was determined to be 7.3 and $9.2 \%$ respectively.

Immunoreactive total human serum ghrelin was measured by a commercially available RIA (Phoenix Pharmaceuticals, Mountain View, CA, USA). Serum ghrelin was measured by using ${ }^{125}$ I-labelled bioactive ghrelin as a tracer and a polyclonal antibody that was raised in rabbits against the C-terminal end of human ghrelin. All samples from individual subjects were measured in the same assay. Intra- and inter-assay coefficients of variation (CV) were 5.3 and $13.6 \%$ respectively.

Serum leptin concentration was measured using an immunofluorometric in-house assay as described previously (34). The lower limit of quantification was $0.1 \mu \mathrm{g} / \mathrm{l}$, and the linear working range was $0.2-40 \mu \mathrm{g} / \mathrm{l}$. Samples measured above this range have been reassayed after dilution in zero standard. Intra-assay variability was $7.4,4.3$ and $5.6 \%$ at leptin concentrations of $0.8,2.5$ and $15.3 \mu \mathrm{g} / \mathrm{l}$ respectively. Inter-assay variability at the same concentrations was
8.3, 5.2 and $5.9 \%$ respectively. Spiking experiments revealed that this immunofluorometric assay (IFMA) for leptin measures total leptin independently from the formation of leptin/leptin receptor complexes.

IGF1 concentrations were measured using an automated chemiluminescent immunoassay (Immulite, Diagnostic Products Corporation, Los Angeles, CA, USA). Immulite IGF1 is a two-site, solid-phase, chemiluminescent enzyme immunometric assay and is standardized according to the World Health Organization's 2nd IS 87/518 (35). IGF1 levels are given as the multiple of age- and gender-adjusted xULN.

Glucose levels were measured from whole venous blood by an automated glucose analyser (Care Eco solo I, Care Diagnostic, Voerde, Germany), and insulin levels were determined by the Adaltis Italia insulin RIA (S.p.A; Casalecchio di Reno, Italy) in the acromegalic patients. In the control group of healthy volunteers, capillary blood glucose concentrations were measured using the glucose oxidase method (Glucometer Biosen 5130, EKFDiagnostic, Magdeburg, Germany), and insulin was measured by a solid phase two-site ELISA (Mercodia AB, Uppsala, Sweden). The lower detection limit was $1 \mathrm{mU} / \mathrm{l}$. The intra- and inter-assay CV were 3.4 and $3 \%$ respectively.

\section{Statistical analysis}

Ten acromegalic patients on peg treatment (peg) were compared to ten gender-, age- and BMI-matched healthy controls (controls), ten acromegalic patients with act disease and ten acromegalic patients with inact disease.

For data analysis, SPSS (version 16.0; SPSS Inc., Chicago, IL, USA) was used. Data were expressed as median and range due to non-normal distribution. For comparison between the groups, first Kruskal-Wallis test for unrelated measurements was used, followed by non-parametrical Mann-Whitney $U$ test for unrelated measurements. For comparison within a group, first Friedman test for related measurements was used to evaluate possible significant differences. If differences were found to be significant, non-parametric Wilcoxon 
signed-rank test for related measurements was used for further calculations. The area under the curve (AUC) was calculated by the trapezoidal rule. The nadir was defined as the lowest value during OGTT for all patients. An adequate suppression of endogenous GH by glucose was defined at a GH nadir $<0.5 \mu \mathrm{g} / \mathrm{l}$. A $P$ value $<0.05$ was considered as the nominal level of significance.

\section{Results}

Age, BMI, fasting glucose and insulin levels were not significantly different between the four groups $(P=$ NS; Table 1$)$.

IGF1 levels given as xULN were significantly higher in act than in the other three groups (peg, $P<0.001$; controls, $P<0.001$; inact, $P<0.001$; Table 1, Fig. 1). Moreover, xULN of IGF 1 was significantly higher in peg compared to controls $(P<0.001)$ and inact $(P<0.05)$, but in controls and in inact, they were not significantly different. Three patients of peg and all act had an IGF1 above the xULN $>1$, whereas none of the controls and none of the inact had elevated IGF1 levels.

Baseline endogenous $\mathrm{GH}$ and the $\mathrm{AUC}_{180}$ of endogenous GH were significantly higher in peg and act compared with controls and inact $\left(P<0.001\right.$, median $\mathrm{AUC}_{180}$ of eGH: peg, $873 \mu \mathrm{g} \mathrm{min} / \mathrm{l}(155-12660 \mu \mathrm{g} \mathrm{min} / \mathrm{l})$; controls, $29 \mu \mathrm{g} \mathrm{min} / \mathrm{l}(18-318 \mu \mathrm{g} \mathrm{min} / \mathrm{l})$; act, $2189 \mu \mathrm{g} \mathrm{min} / \mathrm{l}$ (233-15 $683 \mu \mathrm{g} \mathrm{min} / \mathrm{l}) ;$ inact, $55 \mu \mathrm{g} \mathrm{min/l}(18-258$ $\mu \mathrm{g} \min / \mathrm{l})$ ). But they were not significantly different between peg and act or between controls and inact (Fig. 1). Endogenous GH was adequately suppressed during OGTT in all controls and in all inact, but not in peg or act.

Ghrelin levels significantly decreased during OGTT in acromegalic patients on peg $(P<0.01)$, in controls $(P<0.005)$, in act $(P<0.005)$ and in inact acromegalic patients $(P<0.005)$ with a minimum decrease at $120 \mathrm{~min}$. The percentage decline was $27 \%(-7$ to $46 \%)$ in peg, $17 \%(2-34 \%)$ in controls, $13 \%(5-35 \%)$ in act and $17 \%(8-26 \%)$ in inact. The percentage decline was not significantly different between the four groups (Fig. 2).
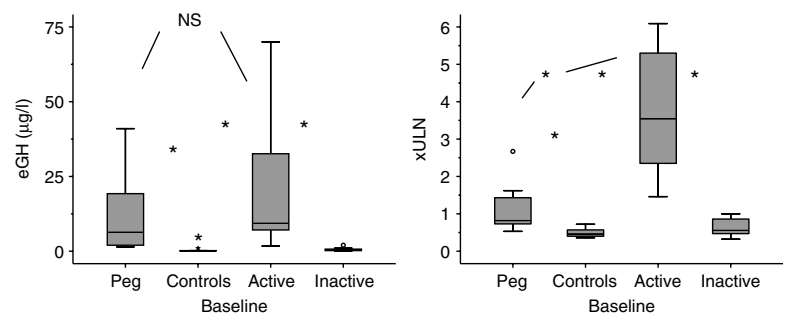

Figure 1 Baseline endogenous GH and xULN of IGF1 levels for the four groups peg, controls, act and inact. ${ }^{*} P<0.001$. Values are given in boxplots showing median and range.
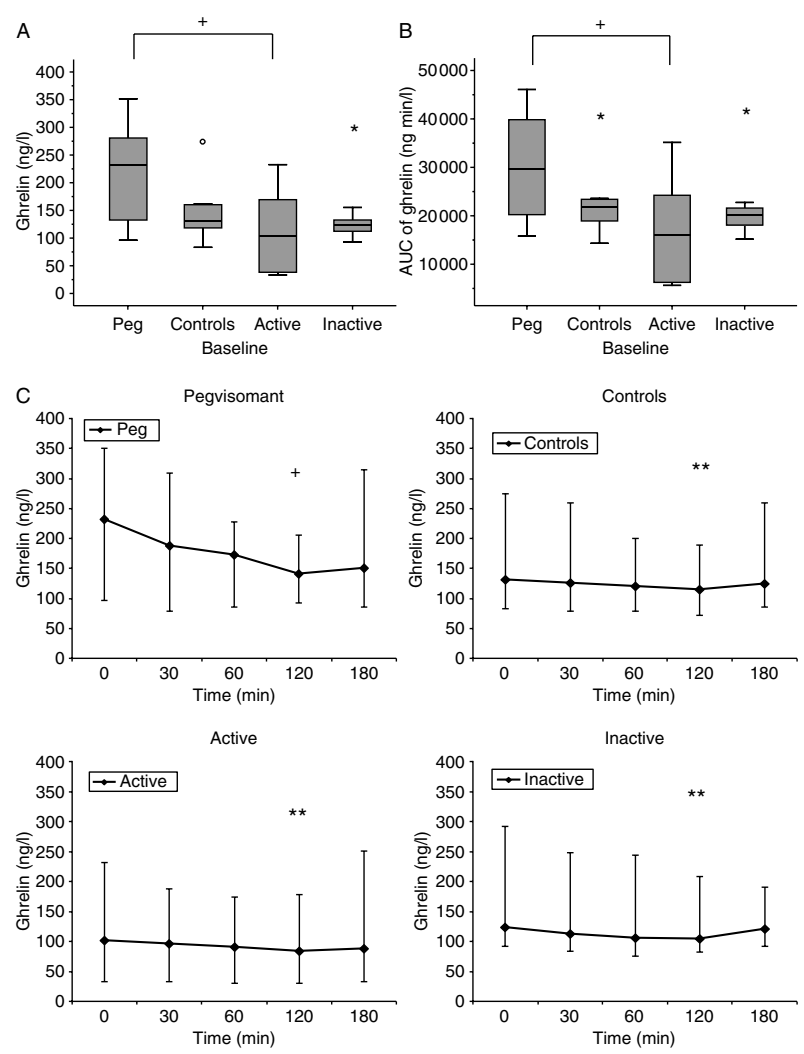

Figure 2 Baseline ghrelin levels $(A)$ and the $A U C_{180}$ of ghrelin (B) for the four investigated groups peg, controls, act and inact. Ghrelin levels during OGTT (C). ${ }^{+} P<0.01,{ }^{\star \star} P<0.005$. Values are given in median and range.

Ghrelin levels at baseline $(P<0.05)$ and the $\mathrm{AUC}_{180}$ of ghrelin $(P<0.05)$ were significantly different between the four groups. Ghrelin levels in act were lower than in healthy controls. In patients with disease control after surgery, ghrelin levels were higher. In peg-treated patients, ghrelin levels were the highest. This difference of high ghrelin levels in acromegalic patients on peg treatment compared with low ghrelin levels in act acromegalic patients reached significance $(P<0.01$ for baseline ghrelin and $\mathrm{AUC}_{180}$ of ghrelin). Ghrelin levels were not significantly different between the other groups (Fig. 2).

Leptin levels slightly but significantly decreased during OGTT in acromegalic patients on peg with a minimum decline at $60 \mathrm{~min}(P<0.005)$, in act $(P<0.05)$ and in inact $(P<0.005)$ acromegalic patients with a minimum decrease at $120 \mathrm{~min}$, but not in the control group. Median percentage decrease was $18 \%$ (3-41\%) in peg, $5 \%$ (-19 to $25 \%$ ) in controls, $18 \%$ $(-1$ to $33 \%)$ in act and $11 \%(0-28 \%)$ in inact. The percentage decline was not significantly different between the four groups (Fig. 3).

Baseline leptin levels were the highest in controls and the lowest in act, but this difference did not reach statistical significance. But the $\mathrm{AUC}_{180}$ of leptin was 

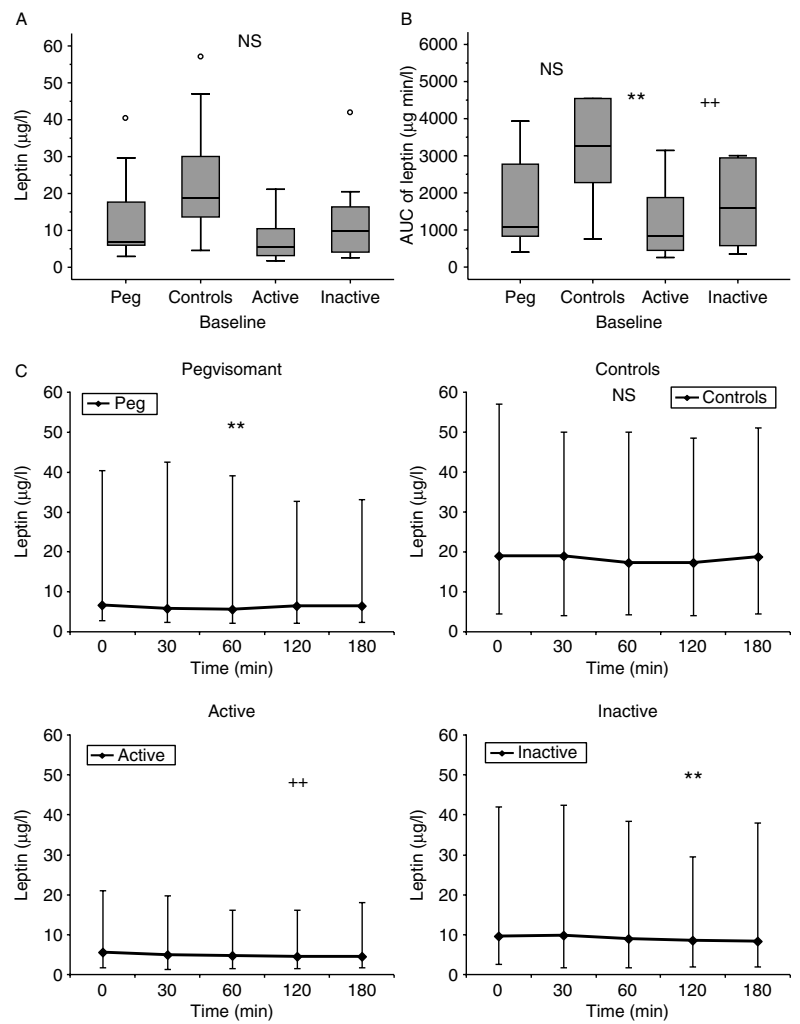

Figure 3 Baseline leptin levels $(A)$ and $A U C_{180}$ of leptin (B) in peg, controls, act and inact. Leptin levels during OGTT (C). ${ }^{* \star} P<0.005$, ${ }^{++} P<0.05$. Values are given in median and range.

significantly different between the groups $(P<0.05)$, which was caused by a significantly higher $\mathrm{AUC}_{180}$ of leptin in controls compared to act $(P<0.005)$ and inact $(P<0.05)$ acromegalic patients (Fig. 3$)$.

\section{Discussion}

We could show for the first time that ghrelin levels are high in acromegalic patients on peg therapy, whereas in acromegalic patients with act disease, ghrelin levels were significantly lower. Previous data have shown that high GH can reduce ghrelin levels in rats (25) as well as in acromegaly $(21,22,36)$ and GH deficiency $(24,37)$, but our data revealed that treatment with the $\mathrm{GH}$ receptor antagonist peg can adequately prevent this effect. So it might be assumed that the direct reducing effect of endogenous $\mathrm{GH}$ on ghrelin could be mediated by the GH receptor. Still, it cannot be ruled out that peg itself increases ghrelin levels independently of $\mathrm{GH}$ and IGF1. In acromegalic patients with inact disease and normalized GH levels as well as in the healthy controls, ghrelin levels tended to be higher than in acromegalic patients with act disease and high GH levels, even if this difference did not reach significance. This missing statistical difference might be due to the rather small investigated groups of only ten patients. Why ghrelin levels in these two groups are lower despite lower xULN levels compared with the peg group is not clear. It might be speculated that $\mathrm{GH}$ secretion and $\mathrm{GH}$ effects in the peg group are somewhat altered.

The physiological regulation of ghrelin by $\mathrm{GH}$ is not yet clarified, even as ghrelin is well known to be a stimulator of GH in the pituitary $(19,20)$. As far as we know, no data exist documenting GH or IGF1 receptors on ghrelin-secreting X/A cells. $\mathrm{GH}$ levels have been shown to rise during peg therapy (2). The reason why $\mathrm{GH}$ levels are lower in our peg-treated patients compared with the act patients in our cohort is probably because our patients on peg were all treated by surgery and many of them by radiotherapy before. It is still a contentious issue whether fat mass has a significant influence on ghrelin levels (38). If this was true, ghrelin levels would be high in act disease as fat mass is reduced and low in inact disease as fat mass is high. Our data confirms that the $\mathrm{GH}$ effect on ghrelin is stronger than the effect of fat mass.

One limitation of this study is that we measured only total ghrelin. Acylated ghrelin is the bioactive form of ghrelin. It interacts with the $\mathrm{GH}$ secretagogue receptor type 1a (GHSR1a) and stimulates GH secretion. The ratio between both ghrelin forms (acylated and desacylated ghrelin) is calculated to be about 1 according to Moller et al. (10) and Tong et al. (39). The lower ratio described in earlier studies by Kim et al. (40) and Lucidi et al. (41) might be due to different assay techniques and changed sampling procedures by known fast degradation of acyl ghrelin. The ratio between both ghrelin forms is closely maintained after food intake (41) or during oral glucose load (40). According to Kim et al. (40), these findings are independent of GH levels. In contrast, Moller et al. (10) found an elevated acyl/desacyl ratio during $\mathrm{GH}$ receptor blockade and a positive correlation between the acyl/desacyl ratio and glucose - a possible influence of elevated ghrelin levels on insulin sensitivity after $\mathrm{GH}$ receptor blockade was discussed by Moller et al. (10). Therefore, more experimental studies are necessary to clarify the effects of ghrelin and the role of ghrelin ratio as well as ghrelin acylation depending on GH levels.

Interestingly, three other studies performed on healthy males did not find an influence of peg on ghrelin levels $(10,32,42)$. Gormsen et al. (42) measured ghrelin levels during a hyperinsulinaemic glucose clamp where they kept insulin and free fatty acid concentrations equal during the experiment to exclude influences of different insulin or free fatty acid levels on ghrelin concentrations. Then, they administered $\mathrm{GH}$ or peg $(30 \mathrm{mg})$ which had no effect on ghrelin concentrations. Muller et al. (32) evaluated the influence of peg on the ghrelin rhythm during fasting. Fasting rapidly induced a diurnal ghrelin rhythm even when peg $(80 \mathrm{mg})$ was administered before. However, GH levels rose higher during additional 
peg treatment. Moller et al. (10) found a higher quotient of acyl/desacyl ghrelin without significant changes in acyl or desacyl ghrelin levels after GH receptor blockade by peg $(15 \mathrm{mg})$ in ten healthy young men. The reason why peg did not affect total ghrelin levels in these studies might be due to the fact that it was performed on healthy males, and only a single peg administration was performed. In our study, the objectives were acromegalic patients on long-term peg therapy.

After glucose load, ghrelin levels decreased significantly in all four groups with a maximum decrease at $120 \mathrm{~min}$. This decline was not significantly different between the four groups. Ghrelin levels are well known to decrease in response to glucose $(16,43)$. The physiological mechanism for that decline is still unknown. The amount of decrease in our groups was similar to that reported in act acromegalic patients before (19 and 26\%) $(26,36)$, but somewhat smaller than described previously in healthy subjects $(28 \%(44)$ and $34 \%(16))$. In these studies, the ghrelin nadir was at 60 min earlier than in our study.

The next main conclusion of our study was that acromegalic patients on peg treatment had similar leptin levels compared with acromegalic patients with act and inact disease. Healthy controls tended to have higher leptin levels compared to the acromegalic patients. This is in accordance to previously published data of our group which also showed similar leptin levels in act, inact and inact acromegalic patients on somatostatin analogues (36). On the other hand, some studies revealed lower leptin levels in act disease $(28$, 29), which is thought to be due to lower fat mass caused by lipolytic GH (45). High levels of GH in acromegaly with act disease lead to a reduction in fat mass compared with the normal population $(28,45)$. Furthermore, leptin is positively correlated to fat mass (13). In contrast to our result that the healthy control group tended to have higher leptin levels than all acromegalic patients, Grottoli et al. reported similar leptin levels in act acromegalic patients and in normal woman (46). Our results indicate that treatment with the $\mathrm{GH}$ receptor antagonist peg does not have a strong impact on leptin levels, as acromegalic patient groups with and without peg therapy showed similar leptin levels.

In 16 acromegalic patients with act disease, treatment with peg led to a rise in leptin levels (33). One reason for these contradictory results may be that in the cited study, all 16 patients had a normalized IGF1 after peg treatment. In our patient group, only $70 \%$ had an IGF1 within the age- and gender-adjusted reference value. The duration of peg therapy might contribute to the leptin levels. However, our patient group was treated much longer (median 47 months) than the patient group of Parkinson's study (mean 7 months).

Leptin levels decreased slightly but significantly after glucose load in all acromegalic patients even during peg therapy. The percentage of decline was not significantly different between the three acromegalic groups.
Leptin levels did not decrease in the healthy control group. A similar decrease in leptin levels after glucose has been reported by our group in GH deficiency with and without GH substitution (11\% in the substituted and $9 \%$ in the non-substituted group) (36) and in a larger group of acromegalic patients (median percentage decline in act disease 18\%) (36). The reason why leptin decreases after glucose load in all acromegalic patients even on peg treatment but not in a healthy control group is unclear. But this finding confirms our previously stated hypothesis that leptin regulation is influenced by chronically high GH levels during act disease (36). A central dysregulation may be involved, which still persists after controlling disease activity. It has been speculated that leptin and GH directly interact $(28,31)$. Some of the GH cells in the pituitary contain leptin granules and have leptin receptors $(31,47)$. Moreover, homozygous mutations of the leptin receptor gene lead to decreased GH secretion (47).

Limitations of the study are small size of the study groups and their inhomogeneity caused by different treatment times with peg, previous treatment such as radiotherapy and surgery and including both genders. Pituitary radiation and pituitary surgery itself may change hypothalamic ghrelin and leptin sensitivity as the GH secretagogue receptor (GHSR) on which ghrelin binds is also located in the hypothalamus (48), and leptin granules and receptors were detected in GH cells of the pituitary $(31,47)$.

\section{Declaration of interest}

J Roemmler received travel grants from Pfizer. B Otto and A M Arafat have nothing to declare. M Bidlingmaier received lecture fees, travel grants and research grants from Pfizer. J Schopohl received lecture fees and travel grants from Pfizer.

\section{Funding}

This research did not receive any specific grant from any funding agency in the public, commercial or not-for-profit sector.

\section{Acknowledgements}

We would like to thank Maja Hoegg for the critical language revisions.

\section{References}

1 Kopchick JJ, Parkinson C, Stevens EC \& Trainer PJ. Growth hormone receptor antagonists: discovery, development, and use in patients with acromegaly. Endocrine Reviews 200223 623-646. (doi:10.1210/er.2001-0022)

2 Janssen JA, Van Der Toorn FM, Hofland LJ, Van Koetsveld P, Broglio F, Ghigo E, Lamberts SW \& Jan Van Der Lely A. Systemic ghrelin levels in subjects with growth hormone deficiency are not modified by one year of growth hormone replacement therapy. European Journal of Endocrinology 2001145 711-716. (doi:10. 1530/eje.0.1450711)

3 Thorner MO, Strasburger CJ, Wu Z, Straume M, Bidlingmaier M, Pezzoli SS, Zib K, Scarlett JC \& Bennett WF. Growth hormone (GH) receptor blockade with a PEG-modified GH (B2036-PEG) lowers 
serum insulin-like growth factor-I but does not acutely stimulate serum GH. Journal of Clinical Endocrinology and Metabolism 1999 84 2098-2103. (doi:10.1210/jc.84.6.2098)

4 Schreiber I, Buchfelder M, Droste M, Forssmann K, Mann K, Saller B \& Strasburger CJ. Treatment of acromegaly with the GH receptor antagonist pegvisomant in clinical practice: safety and efficacy evaluation from the German Pegvisomant Observational Study. European Journal of Endocrinology 2007156 75-82. (doi:10. 1530/eje.1.02312)

5 Paisley AN, Hayden K, Ellis A, Anderson J, Wieringa G \& Trainer PJ. Pegvisomant interference in GH assays results in underestimation of GH levels. European Journal of Endocrinology 2007156 315-319. (doi:10.1530/eje.1.02341)

6 Veldhuis JD, Bidlingmaier M, Anderson SM, Wu Z \& Strasburger CJ. Lowering total plasma insulin-like growth factor I concentrations by way of a novel, potent, and selective growth hormone $(\mathrm{GH})$ receptor antagonist, pegvisomant (B2036-peg), augments the amplitude of GH secretory bursts and elevates basal/nonpulsatile GH release in healthy women and men. Journal of Clinical Endocrinology and Metabolism 200186 3304-3310. (doi:10. $1210 /$ jc.86.7.3304)

7 Drake WM, Rowles SV, Roberts ME, Fode FK, Besser GM, Monson JP \& Trainer PJ. Insulin sensitivity and glucose tolerance improve in patients with acromegaly converted from depot octreotide to pegvisomant. European Journal of Endocrinology 2003149 521-527. (doi:10.1530/eje.0.1490521)

8 Lindberg-Larsen R, Moller N, Schmitz O, Nielsen S, Andersen M, Orskov H \& Jorgensen JO. The impact of pegvisomant treatment on substrate metabolism and insulin sensitivity in patients with acromegaly. Journal of Clinical Endocrinology and Metabolism 2007 92 1724-1728. (doi:10.1210/jc.2006-2276)

9 Higham CE, Rowles S, Russell-Jones D, Umpleby AM \& Trainer PJ. Pegvisomant improves insulin sensitivity and reduces overnight free fatty acid concentrations in patients with acromegaly. Journal of Clinical Endocrinology and Metabolism $2009 \mathbf{9 4}$ 2459-2463. (doi:10.1210/jc.2008-2086)

10 Moller L, Norrelund H, Jessen N, Flyvbjerg A, Pedersen SB, Gaylinn BD, Liu J, Thorner MO, Moller N \& Lunde Jorgensen JO. Impact of growth hormone receptor blockade on substrate metabolism during fasting in healthy subjects. Journal of Clinical Endocrinology and Metabolism 200994 4524-4532. (doi:10. $1210 /$ jc.2009-0381)

11 Plockinger U \& Reuter T. Pegvisomant increases intra-abdominal fat in patients with acromegaly: a pilot study. European Journal of Endocrinology 2008158 467-471. (doi:10.1530/EJE-07-0637)

12 Goto K, Doessing S, Nielsen RH, Flyvbjerg A \& Kjaer M. Growth hormone receptor antagonist treatment reduces exercise performance in young males. Journal of Clinical Endocrinology and Metabolism 200994 3265-3272. (doi:10.1210/jc.2009-0407)

13 Hamann A \& Matthaei S. Regulation of energy balance by leptin. Experimental and Clinical Endocrinology \& Diabetes 1996104 293-300. (doi:10.1055/s-0029-1211457)

14 Horvath TL, Diano S, Sotonyi P, Heiman M \& Tschop M. Minireview: ghrelin and the regulation of energy balance - a hypothalamic perspective. Endocrinology 2001142 4163-4169. (doi:10.1210/en.142.10.4163)

15 Woods SC, Schwartz MW, Baskin DG \& Seeley RJ. Food intake and the regulation of body weight. Annual Review of Psychology 2000 51 255-277. (doi:10.1146/annurev.psych.51.1.255)

16 Shiiya T, Nakazato M, Mizuta M, Date Y, Mondal MS, Tanaka M, Nozoe S, Hosoda H, Kangawa K \& Matsukura S. Plasma ghrelin levels in lean and obese humans and the effect of glucose on ghrelin secretion. Journal of Clinical Endocrinology and Metabolism 200287 240-244. (doi:10.1210/jc.87.1.240)

17 Tschop M, Weyer C, Tataranni PA, Devanarayan V, Ravussin E \& Heiman ML. Circulating ghrelin levels are decreased in human obesity. Diabetes $2001 \quad 50$ 707-709. (doi:10.2337/ diabetes.50.4.707)

18 Date Y, Kojima M, Hosoda H, Sawaguchi A, Mondal MS, Suganuma T, Matsukura S, Kangawa K \& Nakazato M. Ghrelin, a novel growth hormone-releasing acylated peptide, is synthesized in a distinct endocrine cell type in the gastrointestinal tracts of rats and humans. Endocrinology 2000141 4255-4261. (doi:10. 1210/en.141.11.4255)

19 Otto B, Spranger J, Benoit SC, Clegg DJ \& Tschop MH. The many faces of ghrelin: new perspectives for nutrition research? British Journal of Nutrition 200593 765-771. (doi:10.1079/ BJN20051446)

20 Takaya K, Ariyasu H, Kanamoto N, Iwakura H, Yoshimoto A, Harada M, Mori K, Komatsu Y, Usui T, Shimatsu A, Ogawa Y, Hosoda K, Akamizu T, Kojima M, Kangawa K \& Nakao K. Ghrelin strongly stimulates growth hormone release in humans. Journal of Clinical Endocrinology and Metabolism 200085 4908-4911. (doi:10.1210/jc.85.12.4908)

21 Cappiello V, Ronchi C, Morpurgo PS, Epaminonda P, Arosio M, Beck-Peccoz P \& Spada A. Circulating ghrelin levels in basal conditions and during glucose tolerance test in acromegalic patients. European Journal of Endocrinology 2002147 189-194. (doi:10.1530/eje.0.1470189)

22 Kawamata T, Inui A, Hosoda $\mathrm{H}$, Kangawa $\mathrm{K} \&$ Hori $\mathrm{T}$. Perioperative plasma active and total ghrelin levels are reduced in acromegaly when compared with in nonfunctioning pituitary tumours even after normalization of serum GH. Clinical Endocrinology 200767 140-144. (doi:10.1111/j.1365-2265. 2007.02851.x)

23 Jarkovska Z, Rosicka M, Marek J, Hana V, Weiss V, Justova V, Lacinova Z, Haluzik M \& Krsek M. Plasma levels of total and active ghrelin in acromegaly and growth hormone deficiency. Physiological Research 200655 175-181.

24 Eden Engstrom B, Burman P, Holdstock C \& Karlsson FA. Effects of growth hormone $(\mathrm{GH})$ on ghrelin, leptin, and adiponectin in GH-deficient patients. Journal of Clinical Endocrinology and Metabolism $2003 \quad 88$ 5193-5198. (doi:10.1210/jc.2003030713)

25 Tschop M, Flora DB, Mayer JP \& Heiman ML. Hypophysectomy prevents ghrelin-induced adiposity and increases gastric ghrelin secretion in rats. Obesity Research 200210 991-999. (doi:10. 1038/oby.2002.135)

26 Freda PU, Reyes CM, Conwell IM, Sundeen RE \& Wardlaw SL. Serum ghrelin levels in acromegaly: effects of surgical and long-acting octreotide therapy. Journal of Clinical Endocrinology and Metabolism 200388 2037-2044. (doi:10.1210/jc.2002-021683)

27 Kozakowski J, Rabijewski M \& Zgliczynski W. Decrease in serum ghrelin levels in patients with acromegaly normalize after successful surgical treatment. Endokrynologia Polska $2005 \mathbf{5 6}$ $862-870$.

28 Miyakawa M, Tsushima T, Murakami H, Isozaki O, Demura H \& Tanaka T. Effect of growth hormone $(\mathrm{GH})$ on serum concentrations of leptin: study in patients with acromegaly and $\mathrm{GH}$ deficiency. Journal of Clinical Endocrinology and Metabolism 1998 83 3476-3479. (doi:10.1210/jc.83.10.3476)

29 Damjanovic SS, Petakov MS, Raicevic S, Micic D, Marinkovic J, Dieguez C, Casanueva FF \& Popovic V. Serum leptin levels in patients with acromegaly before and after correction of hypersomatotropism by trans-sphenoidal surgery. Journal of Clinical Endocrinology and Metabolism 200085 147-154. (doi:10.1210/ jc.85.1.147)

30 Tan KC, Tso AW \& Lam KS. Effect of Sandostatin LAR on serum leptin levels in patients with acromegaly. Clinical Endocrinology 200154 31-35. (doi:10.1046/j.1365-2265.2001.01180.x)

31 Popovic V, Damjanovic S, Dieguez C \& Casanueva FF. Leptin and the pituitary. Pituitary 2001 4 7-14. (doi:10.1023/A:10129 $38308654)$

32 Muller AF, Lamberts SW, Janssen JA, Hofland LJ, Koetsveld PV, Bidlingmaier M, Strasburger CJ, Ghigo E \& Van Der Lely AJ. Ghrelin drives GH secretion during fasting in man. European Journal of Endocrinology 2002146 203-207. (doi:10.1530/eje.0.1460203)

33 Parkinson C, Whatmore AJ, Yates AP, Drake WM, Brabant G, Clayton PE \& Trainer PJ. The effect of pegvisomant-induced serum IGF-I normalization on serum leptin levels in patients with acromegaly. Clinical Endocrinology 200359 168-174. (doi:10. $1046 /$ j.1365-2265.2003.01795.x) 
$34 \mathrm{Wu} \mathrm{Z}$, Bidlingmaier M, Liu C, De Souza EB, Tschop M, Morrison KM \& Strasburger CJ. Quantification of the soluble leptin receptor in human blood by ligand-mediated immunofunctional assay. Journal of Clinical Endocrinology and Metabolism 2002 87 2931-2939. (doi:10.1210/jc.87.6.2931)

35 Bristow AF, Gooding RP \& Das RE. The International Reference Reagent for insulin-like growth factor-I. Journal of Endocrinology 1990125 191-197. (doi:10.1677/joe.0.1250191)

36 Roemmler J, Otto B, Steffin B, Bidlingmaier M \& Schopohl J. Serum leptin and ghrelin levels in active and inactive acromegalic patients during an oral glucose tolerance test. Experimental and Clinical Endocrinology \& Diabetes 2009117 135-141. (doi:10. 1055/s-2008-1078739)

37 Giavoli C, Cappiello V, Corbetta S, Ronchi CL, Morpurgo PS, Ferrante E, Beck-Peccoz P \& Spada A. Different effects of short- and long-term recombinant hGH administration on ghrelin and adiponectin levels in GH-deficient adults. Clinical Endocrinology $2004 \quad 61$ 81-87. (doi:10.1111/j.1365-2265. 2004.02067.x)

38 Malik IA, English PJ, Ghatei MA, Bloom SR, Macfarlane IA \& Wilding JP. The relationship of ghrelin to biochemical and anthropometric markers of adult growth hormone deficiency. Clinical Endocrinology 200460 137-141. (doi:10.1111/j.13652265.2004.01929.x)

39 Tong J, Tschop MH, Aulinger BA, Davis HW, Yang Q, Liu J, Gaylinn BD, Thorner MO, D'alessio D \& Tso P. The intestinal lymph fistula model - a novel approach to study ghrelin secretion. American Journal of Physiology. Gastrointestinal and Liver Physiology 2010298 G474-G480. (doi:10.1152/ajpgi.00367.2009)

40 Kim SW, Kim KW, Shin CS, Park Do J, Park KS, Cho BY, Lee HK \& Kim SY. Acylated ghrelin secretion is acutely suppressed by oral glucose load or insulin-induced hypoglycemia independently of basal growth hormone secretion in humans. Hormone Research 200767 211-219. (doi:10.1159/000097098)

41 Lucidi P, Murdolo G, Di Loreto C, Parlanti N, De Cicco A, Ranchelli A, Fatone C, Taglioni C, Fanelli C, Santeusanio F \&
De Feo P. Meal intake similarly reduces circulating concentrations of octanoyl and total ghrelin in humans. Journal of Endocrinological Investigation 200427 RC12-RC15.

42 Gormsen LC, Nielsen C, Gjedsted J, Gjedde S, Vestergaard ET, Christiansen JS, Jorgensen JO \& Moller N. Effects of free fatty acids, growth hormone and growth hormone receptor blockade on serum ghrelin levels in humans. Clinical Endocrinology 200766 641-645. (doi:10.1111/j.1365-2265.2007.02786.x)

43 Soriano-Guillen L, Barrios V, Martos G, Chowen JA, CamposBarros A \& Argente J. Effect of oral glucose administration on ghrelin levels in obese children. European Journal of Endocrinology 2004151 119-121. (doi:10.1530/eje.0.1510119)

44 Caixas A, Bashore C, Nash W, Pi-Sunyer F \& Laferrere B. Insulin, unlike food intake, does not suppress ghrelin in human subjects. Journal of Clinical Endocrinology and Metabolism 2002871902. (doi:10.1210/jc.87.4.1902)

45 Bolanowski M, Milewicz A, Bidzinska B, Jedrzejuk D, Daroszewski J \& Mikulski E. Serum leptin levels in acromegaly - a significant role for adipose tissue and fasting insulin/glucose ratio. Medical Science Monitor 20028 CR685-CR689.

46 Grottoli S, Gasco V, Mainolfi A, Beccuti G, Corneli G, Aimaretti G, Dieguez C, Casanueva F \& Ghigo E. Growth hormone/insulin-like growth factor I axis, glucose metabolism, and lypolisis but not leptin show some degree of refractoriness to short-term fasting in acromegaly. Journal of Endocrinological Investigation 200831 1103-1109.

47 Lloyd RV, Jin L, Tsumanuma I, Vidal S, Kovacs K, Horvath E, Scheithauer BW, Couce ME \& Burguera B. Leptin and leptin receptor in anterior pituitary function. Pituitary 20014 33-47. (doi:10.1023/A:1012982626401)

48 Kojima M, Hosoda H, Date Y, Nakazato M, Matsuo H \& Kangawa K. Ghrelin is a growth-hormone-releasing acylated peptide from stomach. Nature 1999402 656-660. (doi:10.1038/45230)

Received 5 August 2010

Accepted 10 August 2010 